\title{
Statistical Comparison of Parallel-Line Symmetrical Microbiological Models: Analysis of Agar Diffusion Assay in $8 \times 8$ Large Rectangular Plates
}

\author{
Dalia EISSA ${ }^{1}$, Engy RASHED ${ }^{2}$, Mostafa EISSA ${ }^{3, *}$ \\ ${ }^{1}$ Royal Oldham Hospital; Oldham; United Kingdom; eissade@yahoo.com \\ ${ }^{2}$ National Centre for Radiation Research and Technology; Cairo; Egypt; engyrefaat@yahoo.com \\ Independent Researcher; Pharmaceutical Research Facility; Cairo, Egypt; mostafaessameissa@yahoo.com \\ Orcid: 0000-0002-6340-8973¹ Orcid: 0000-0002-6593-378X² Orcid: 0000-0002-6340-89733 \\ *Correspondence Author, e-mail: mostafaessameissa@yahoo.com
}

\begin{abstract}
Background: Microbiological assay of active medicinal compounds is superior to conventional chemical means in several circumstances to date. However, ensuring the validity and suitability of the assay design proposed for the intended purpose is crucial before deriving any records or conclusions from the results of the potency determination; (2) The present work represented statistical comparison between three design models for determination of the potency of Neomycin Sulfate antibiotic using agar diffusion technique for the same test material subject under identical conditions through the application of a combination of statistical software programs, including validated programmed Microsoft Excel Workbook for the statistical testing of each assay layout; (3) Results: raw data of the three assay designs were found to be reasonably valid for further analysis of the assay suitability. Examination of the sources of variations for each design demonstrated the validity of the conducted experimentation. Variation between the computed potencies from the three designs was lower than 5 $\mu \mathrm{g} / \mathrm{mg}$. However, there was significant variation between the confidence windows of each type; (4) Conclusions: 2 $\mathrm{x} 4$ design had the narrowest confidence range. However, improving confidence would require investigation of the assay parameters, including the modification of the number of replicates per treatment.
\end{abstract}

Keywords: Agar Diffusion; ANOVA; Confidence Limit; Homoscedasticity; Neomycin Sulfate; Normality; Outlier; PLM; Potency; Two-Dose Symmetrical Assay

\section{Introduction}

Statistical evaluation of the suitability of assays for active medicinal materials is a pivotal task to be performed before conducting any further computations to estimate the biological activity of the subject [1]. Till nowadays, a microbiological assay of antimicrobials is still mandated by the official monographs for some antibiotics [2]. It is common for an antibiotic to be composed of a mixture of related active constituents or components [3]. It is a common practice to isolate and discover the most desired component from several compounds produced from the fermentation and industrial processes [3]. Also, finding the needed conditions to direct the biosynthesis or manufacturing of this active material of interest would be a desirable needed step.

However, there are many cases where the commercially available products in the market include raw materials that remain as a mixture of varying proportions of related substances such as members of the aminoglycoside antibiotics [4]. A prominent example, Neomycin represents a particularly interesting and challenging problem. It is composed of Neomycin B and Neomycin C, which are glycosides of the organic base Neamine (basically called Neomycin A) [5]. In commercially available Neomycin, factor B 
is the major constituent and has greater antibiotic activity than factor $\mathrm{C}$ against a range of organisms. There is sometimes a small proportion of Neamine that has little activity [6,7]. Neomycin B and C are of the same molecular weight and they are different only in the aminoethyl group configuration and could not be easily separated by conventional analytical procedures [6].

The prime challenges in the microbiological antibiotic assay were discussed by a biological standard investigator in the early 1960s. One problem referred to the difficulty in obtaining agreement between successive assays in either the same or different laboratories [8]. The researcher had cited the reason for the lack of reproducibility as being the variable influence on the two active components of changes in $\mathrm{pH}$, media composition, temperature, and the test organism culture age [8]. More deeply, A scientist and his coworkers in 1964 discussed the variable attitude of B and C fractions in the agar diffusion test depending on the constituents of the assay medium and especially its salt content [9]. They demonstrated that by choice of a medium of low ionic content and the right test organism [10]. An assay system design could be arranged in which components $\mathrm{B}$ and $\mathrm{C}$ showed an equivalent potency. However, unless it could be shown that Neomycin B and C were equipotent against a range of typical infecting organisms in vivo, then such an approach might conceal rather than solves the problem [6].

A study of commercially available Neomycin from several countries was made for the World Health Organization (WHO) 1970. It revealed that the then-current International Reference Preparation was unrepresentative of commercially available material about proportions of components B and C [11]. Wilson and colleagues in 1973 showed by gas liquid chromatography (GC) that in Neomycin products available on the Canadian market, the proportion of neomycin C variation ranged within $28.5 \%$ [12]. Finally, Generally, Lightbown (1961) concluded the following: 1- For heterogeneous materials controlled biologically and assayed against a heterogeneous standard, it must be recognized that there is no true potency for any sample. 2- A sample will have a family of potencies depending on the conditions of the assay. These may be distributed about a mode, but the modal value has no intrinsic superiority over any individual value [9].

Recently, risk mitigation for the above problem could be achieved through standardization of the testing conditions according to the compendial chapters [13]. A further improvement might be reached by harmonization between the official reference monographs [14,15]. This embraced formulas for assay media which are available from pharmacopeias and various other publications [16]. Those for the assay of growth-inhibiting substances tend to be rather simple and based on natural nutrients. However, several assay designs have been devised for microbiological antibiotic potency determinations using zone inhibition [6]. Apart from the systematic validation of the assay, routine potency determination testing should be investigated for the suitability and quality of the experiment before calculating the actual activity of the antimicrobial substance.

The present work aimed to study three different designs for antibiotic potency determination using a balanced two-dose Parallel Line Model (PLM) in large rectangular $32 \mathrm{~cm}$ x $32 \mathrm{~cm}$ autoclavable agar plates using a case of Neomycin Sulfate raw material against working standard. The study covered statistical analysis of the validity of the examined designs before computing the potency and comparison of the quality of the outcome from the three experiment layouts. This statistical investigation would serve as the basis for the Quality Control (QC) analyst of stepwise zone inhibition dataset analysis from the regular laboratory activity in order to derive valid potency determination data.

\section{Materials and Methods}

\subsection{Study subject}

The powdered raw material of Neomycin Sulfate was assayed in large autoclavable $32 \mathrm{~cm} \times 32 \mathrm{~cm}$ rectangular plates against a reference working standard of known potency (expressed as $\mu \mathrm{g} / \mathrm{mg}$ ) [17]. Three types of designs were used for potency determination under identical testing conditions as stated in the compendial method after the post-validation assessment [5-7]. Results were expressed as a zone of inhibition diameter (in $\mathrm{mm}$ ) recorded to the nearest $0.01 \mathrm{~mm}$ at the edge boundaries [18]. This distinctive zone was a clear circular area of the agar medium surrounded by opaque growth space [19]. Raw data were stored in Excel Sheet files for further processing.

\subsection{Assay design types}


Balanced PLM using a two-dose level was used with randomization of the treatment groups across rows and columns. Three antimicrobial activity determinations were accessed based on the number of Preparations (P) and Treatments (T) per a single plate i.e. ( $\mathrm{P} \times \mathrm{T})$ [8]. These designs comprised two preparations and four treatments $(2 \times 4)$, two preparations and eight treatments $(2 \times 8)$ and four preparations and eight treatments $(4 \times 8)$. The first design included 16 replicates per one treatment. While the remaining treatments in the other layouts included groups of eight replicates [8].

\subsection{Preliminary statistical analysis for data visualization}

Initial evaluation of the scrambled and unscrambled datasets was conducted using Graphpad Prism V9 and Minitab V16 [20,21]. Data central tendency, pattern and spreading were examined through descriptive statistical analysis, outlier detection, normality testing and assessing the homogeneity of variances. If any true aberrant value was detected, it should be investigated for possible omission and replacement. Additional data visualization could be accomplished through screening different types of means with Confidence Limits (CL), percentiles, standard deviations (SD), Coefficient of Variations (CV), skewness and kurtosis. The graphical drawing was performed using Microsoft Excel 2016, GraphPad Prism and Minitab programs [20-23].

\subsection{Analysis of the experimental sources of variation}

Systematic analysis of the sources of variation in the assay was conducted using Analysis of Variance (ANOVA). Stepwise examination of datasets for each design was programmed in Excel Workbook according to Hewitt using provided model examples as a reference for validation. Empirically selected probability levels $(\mathrm{P})$ for the variance criteria were selected as shown in Table 1 [6]. The potential sources of variations in the potency assay were the effect of preparation, row/column variation, the contrast of the standard and the unknown in the duplicate preparations, deviation from the parallelism and regression analysis.

Table 1. Selected probability limit for sources of variation in the experiment for the analysis of variance (ANOVA) [6].

\begin{tabular}{ll}
\hline \multicolumn{1}{c}{ Source of Variance } & Arbitrary Probability Level, $\mathbf{P}$ \\
\hline Preparation & 0.050 \\
\hline Regression & 0.001 \\
Parallelism (deviation from) & 0.050 \\
\hline Contrast of standard & 0.200 \\
Contrast of unknown & 0.200 \\
Contrast of standard slope & 0.200 \\
Contrast of unknown slope & 0.200 \\
\hline Rows & 0.050 \\
Columns & 0.050 \\
\hline
\end{tabular}

\subsection{Estimated activity determinations from valid assays}

Excel sheets that were used in the previous analysis were extended to cover the computation of the potency of the unknown material using the known potency of the standard in the relation between the zone of inhibition (in $\mathrm{mm}$ ) as a response in the $\mathrm{y}$-axis and the logarithm of the potency to the base ten interpreted at x-axis [24]. The confidence intervals were calculated also in the program according to Hewitt methodology described in detail [25]. The final result of the potency estimate would be expressed in $\mu \mathrm{g} / \mathrm{mg}$ units. All equations for the computation were included in the Excel worksheet and validated against detailed examples [26]. Graphical presentations were done using Both GraphPad Prism and Minitab software. 


\section{Results}

Microbiological analysis using agar diffusion test - for the determination of the potency of the antibiotic Neomycin Sulfate - was assessed statistically using three types of PLM designs for the assay of one unknown against standard of known biological activity in large rectangular $32 \mathrm{~cm} \times 32 \mathrm{~cm}$ plates as discussed in the following steps.

\subsection{Preliminary statistical evaluation of the validity of the dataset}

\subsubsection{High and low doses assessment for treatment groups and the descriptive analysis}

Preliminary visual examination of the dataset for each treatment in Figure 1 showed visually the parallelism of each dose pair (high $(\mathrm{H})$ and low $(\mathrm{L})$ ) without any noticeable deviations. Maximum Standard Deviation of the Mean (S.D.) was found in the reference group low dose treatment (SBL) followed by U3L two preparations x eight treatments and four preparations $x$ eight treatments designs, respectively. While the lowest value was found in the high dose of the unknown (UH) in two preparations $x$ four treatments design. In general, all low doses of the standard and test preparations except for SL - showed higher SEM than the corresponding high doses. The relative deviation percent of the means from medians relative to the average values for each treatment group were $0.00,0.45,0.16$, 1.40, 0.45, 1.17, 0.16, -0.96, 0.25 and 0.50 for SAH, SAL, SBH, SBL, UAH, UAL, U8H, U8L, UH, UL, SH, SL, U1H, U1L, U2H, U2L, U3H, U3L, S8H and S8L, respectively (Table 2 and Figure 1). The coefficient of Variation (CV) range was relatively narrow ranging from 1.38 for $\mathrm{U} 1 \mathrm{H}$ to 4.09 for SBL. Thus, data spreading around the center point would be minimal. It should be noted that Geometric Standard Deviation Factor (GSDF) followed the same order as CV\% for the treatment groups. All values of GSDF were close to one.

Four types of means were used in the current analysis, namely: Arithmetic Mean (M), Geometric Mean (GM), Harmonic Mean (HM) and Quadratic Mean (QM) providing a measure of the central tendency. The deviation between these mean types did not exceed $4 \%$ between M and HM for SBL and U3L. The overall gap is slightly higher between $\mathrm{M}$ and HM than between HM and QM. In addition, 95\% Confidence Interval (CI) for these means almost coincided with each other. Under ideal situations when all values per treatment group are the same, all means would yield the same value. Since the data were homogenous, the variations were very small. These observations were demonstrated in Table 2 numerically and complemented by Figure 2 visually. Skewness and kurtosis provided quantitative measures for the deviation of the datasets from the typical Gaussian pattern. In the present case, groups of 16 readings of $2 \times 4$ assay showed the minimum deviation from the expected bell-shaped, except SL. The highest distortion from the normal behavior could be spotted with U3L and UAL in the experiments involving eight replicates per the treatment group.

\subsubsection{Normality of data distribution}

QQ plot in Figure 3 showed the closeness of the record points to the straight line of the theoretical normality of the distribution. All points were reasonably close to the red dotted line signifying acceptable normality level. Datasets showed two groups of clusters in both graphs illustrating high and low doses of standard and test groups. Extreme results were shown in-between and at the edges of those treatment clusters. At $\alpha=0.05$, the results of $K_{2}$ normality tests for $S_{A H}, S_{A L}, S_{B H}, S_{B L}, U_{A H}, U_{A L}, U_{8 H}$, $\mathrm{U}_{8 \mathrm{~L}}, \mathrm{U}_{\mathrm{H}}, \mathrm{U}_{\mathrm{L}}, \mathrm{S}_{\mathrm{H}}, \mathrm{S}_{\mathrm{L}}, \mathrm{U}_{1 \mathrm{H}}, \mathrm{U}_{1 \mathrm{~L}}, \mathrm{U}_{2 \mathrm{H}}, \mathrm{U}_{2 \mathrm{~L}}, \mathrm{U}_{3 \mathrm{H}}, \mathrm{U}_{3 \mathrm{~L}}, \mathrm{~S}_{8 \mathrm{H}}$ and $\mathrm{S}_{8 \mathrm{~L}} \mathrm{using} \mathrm{D}^{\prime}$ Agostino \& Pearson omnibus normality test were $0.7669,3.272,1.048,2.442,1.855,6.133,0.7377,1.023,5.590,1.175,0.1962,5.130,1.607,1.961$, $1.512,0.1443,0.7450,5.661,0.6315$ and 3.455 with $p$-values of $0.6815,0.1948,0.5923,0.2949,0.3955,0.0466$, $0.6915,0.5996,0.0611,0.5558,0.9066,0.0769,0.4477,0.3751,0.4695,0.9304,0.6890,0.0590,0.7292$ and 0.1777 , respectively. Thus, all treatment groups passed the normality test - with a p-value that was not significant - except $\mathrm{U}_{\mathrm{AL}}(\mathrm{P} \leq 0.05)$.

Similar results were obtained using KS normality test with KS - in the same order - distance of 0.1965, $0.2500,0.1929,0.2148,0.1942,0.3100,0.1638,0.2478,0.1639,0.1658,0.1761,0.1754,0.2399,0.2495,0.2433$, $0.2437,0.1856,0.2406,0.2033$ and 0.2610 and p-values of $0.2000,0.1599,0.2000,0.2000,0.2000,0.0228$, $0.2000,0.1699,0.2000,0.2000,0.2000,0.2000,0.2000,0.1623,0.2000,0.2000,0.2000,0.2000,0.2000$ and 0.1163. However, Shapiro-Wilk normality test showed another group ( $\left.\mathrm{U}_{1 \mathrm{~L}}\right)$ that deviated from normal distribution $(\mathrm{P} \leq 0.05)$. W statistics were 0.9471, 0.9231, 0.9699, 0.8778, 0.8829, 0.8162, 0.9325, 0.9297, 
$0.9048,0.9341,0.9603,0.9072,0.8859,0.7940,0.8862,0.8982,0.9659,0.8837,0.9392$ and 0.9192 with pvalues $0.6821,0.4553,0.8970,0.1793,0.2008,0.0425,0.5389,0.5130,0.0958,0.2832,0.6664,0.1051,0.2142$, $0.0247,0.2158,0.2786,0.8643,0.2041,0.6031$ and 0.4237 , respectively. Nevertheless, the deviation in normality of $U_{A L}$ and $U_{1 L}$ was not serious since both groups passed normality in all tests at $\alpha=0.01$.

\subsubsection{Analysis of outliers in the datasets of the experimental antibiotic designs}

Implementation of the USP method for outlier detection using G value limit for upper and lower values showed only one outlier from the smallest figure of $U_{\mathrm{AL}}(0.789$ which is slightly greater than the limiting $\mathrm{G}$ value of 0.780 ) in $2 \times 8$ experimental design. However, the absence of aberrant values was confirmed using the ROUT method at $\mathrm{Q}=1.0 \%$. The result of the USP outlier test could be explained by that, there was a clustering tendency observed within the impacted group toward the upper values which might affect the outcome of the test. Nevertheless, this figure - by experience and trend observation - was found to be normal and not unusual. The outcome of the ROUT method was also confirmed with Grubbs' Test for outliers - at the significance level of $\alpha=0.05$ - where the null hypothesis assumption was that all data values have come from the same normal population.

On the other hand, the alternative hypothesis was based on that the smallest or largest data value was considered an outlier. In $4 \times 8$ design $\mathrm{U}_{1 \mathrm{H}}, \mathrm{U}_{1 \mathrm{~L}}, \mathrm{U}_{2 \mathrm{H}}, \mathrm{U}_{2 \mathrm{~L}}, \mathrm{U}_{3 \mathrm{H}}, \mathrm{U}_{3 \mathrm{~L}}, \mathrm{~S}_{8 \mathrm{H}}$ and $\mathrm{S}_{8 \mathrm{~L}}$ treatments had $(\mathrm{G}, \mathrm{P})$ results of $(1.57,0.724),(1.57,0.726),(1.40,1.000),(1.64,0.594),(1.81,0.319),(2.10,0.061),(1.58,0.697)$ and (1.99, $0.129)$, respectively. The same was found in the $2 \times 4$ design with $(G, P)$ statistics $(1.47,1000),(1.93$, $0.654),(1.92,0.686)$ and $(2.30,0.181)$ for $U_{H}, U_{L}, S_{H}$ and $S_{L}$, respectively. For 2 x 8 design, $S_{A H}, S_{A L}, S_{B H}, S_{B L}$, $\mathrm{U}_{\mathrm{AH}}, \mathrm{U}_{\mathrm{AL}}, \mathrm{U}_{\mathrm{BH}}$ and $\mathrm{U}_{\mathrm{BL}},(\mathrm{G}, \mathrm{P})$ pair calculation was $(1.54,0.788),(1.98,0.135),(1.82,0.304),(1.87,0.243)$, $(1.50,0.890),(2.09,0.068),(1.46,0.982),(1.45,1.000)$, respectively. Accordingly, a decision has been made to continue the analysis without removing this suspected value.

\subsubsection{Homogeneity of variances (homoscedasticity) within experimental designs}

The assumption of the null hypothesis in the analysis of equal variances is that all variances are equal. On the other hand, the alternative hypothesis assumed that at least one variance is different at significance level $\alpha=0.05$. In $2 \times 8$ design, $\mathrm{S}_{\mathrm{AH}}, \mathrm{S}_{\mathrm{AL}}, \mathrm{S}_{\mathrm{BH}}, \mathrm{S}_{\mathrm{BL}}, \mathrm{U}_{\mathrm{AH}}, \mathrm{U}_{\mathrm{AL}}, \mathrm{U}_{\mathrm{BH}}$ and $\mathrm{U}_{\mathrm{BL}}$ showed 95\% Bonferroni CI for S.D. of (0.307977 to 1.67726$)$, (0.232627 to 4.25447$)$, (0.307626 to 3.30808), (0.251840 to 4.91992), (0.166974 to 1.16824$),(0.108259$ to 4.16752$),(0.202711$ to 1.20854$)$ and (0.347617 to 2.01593$)$, respectively. For $\mathrm{U}_{\mathrm{H}}, \mathrm{U}_{\mathrm{L}}, \mathrm{S}_{\mathrm{H}}$ and $\mathrm{S}_{\mathrm{L}}$ in $2 \times 4$ design, $\mathrm{CI}$ was (0.321898 to 1.22862), (0.578193 to 2.71302), (0.922316 to $2.64605)$ and (0.673005 to 1.78064$)$, respectively.

Complementarily, the $4 \times 8$ design of $\mathrm{U}_{1 \mathrm{H}}, \mathrm{U}_{1 \mathrm{~L}}, \mathrm{U}_{2 \mathrm{H}}, \mathrm{U}_{2 \mathrm{~L}}, \mathrm{U}_{3 \mathrm{H}}, \mathrm{U}_{3 \mathrm{~L}}, \mathrm{~S}_{8 \mathrm{H}}$ and $\mathrm{S}_{8 \mathrm{~L}}$ showed CI $(0.142608$ to $1.21647)$, (0.187204 to 3.06863), (0.185335 to 1.39826$),(0.189558$ to 1.83306$),(0.220910$ to 2.18828), (0.244200 to 4.90146$),(0.300196$ to 1.70512$),(0.229401$ to 4.37330$)$, respectively. The individual confidence level for the three assay designs was $99.38 \%, 98.75 \%$ and $99.38 \%$ for the three experimental designs, respectively. Levene test statistics for the three assays in the same experimental design order were 0.73 , 2.12 and 0.55 . In the summary plot of Figures $3-5$, the p-values for all treatments in each experimental group are greater than the common significance level of 0.05 . None of the differences between the groups are statistically significant, and all the comparison intervals overlap.

\subsection{Statistical evaluation of the assay suitability system}

Experimental sources of variation were investigated using analysis of variance (ANOVA) to exclude the inefficiency of the assay tests. In general, variance ratios showed satisfactory outcomes for different sources of variation from each test design as could be found in Tables 4, 5 and 6. Linear regression parameter should be fairly large above the critical limiting value. Deviation from parallelism was fairly below 4.05 and 2.83 limiting values. The calculated probability of linear regression should be significant $((<0.05)$ to compute the $95 \%$ confidence limit. The same also applied for non-parallelism but it should be not significant i.e. $\geq 0.05$. Thus, the pharmacopeial criteria have been fulfilled. Other sources of variations that are non-official include the effect of preparation and the columns/rows matrix in large plates (such as $8 \times 8$ in this case) which were all within the acceptable limits. Effect of duplication in $4 \times$ 8 assay has another special inspection characteristic which embraced the contrast of both the standard and the unknown. The variance ratios for these properties were well below the limiting value of 1.70 . 
Thus, it could be concluded that there are no signs for invalidating the assay and the process of potency determination could be conducted.

\subsection{Potency determination of the antibiotic and establishing confidence limit for each design type}

After confirmation of the validity and suitability of the assay design for the determination of Neomycin Sulfate antimicrobial potency, the microbiological activity for the active raw material was calculated for each design and the confidence range was established. The calculated antibiotic activity of the active medicinal material for the three designs was 745.87, 746.04 and $750.65 \mu \mathrm{g} / \mathrm{mg}$ for $2 \times 8,4 \times 8$ and $2 \times 4$ designs, respectively. The upper and lower confidence limits percent (at $\mathrm{p}=0.95)$ were as the following in the same order: $(124.66 \%, 80.22 \%),(114.30 \%, 87.49 \%)$ and $(109.47 \%, 86.95 \%)$ corresponding to (929.82 $\mu \mathrm{g} / \mathrm{mg}, 598.31 \mu \mathrm{g} / \mathrm{mg}),(852.71 \mu \mathrm{g} / \mathrm{mg}, 652.72 \mu \mathrm{g} / \mathrm{mg})$ and $(821.77 \mu \mathrm{g} / \mathrm{mg}, 685.69 \mu \mathrm{g} / \mathrm{mg})$, respectively. The confidence limit percent range was $18.1 \%, 26.8$ and $44.4 \%$ for $2 \times 4,4 \times 8$ and $2 \times 8$ designs, respectively. These findings could be visualized in Figure 7 in the individual value plot and potency diagram with the corresponding confidence thresholds for each microbiological rectangular plate design.

Colum n Graph (Mean \pm S.D.)

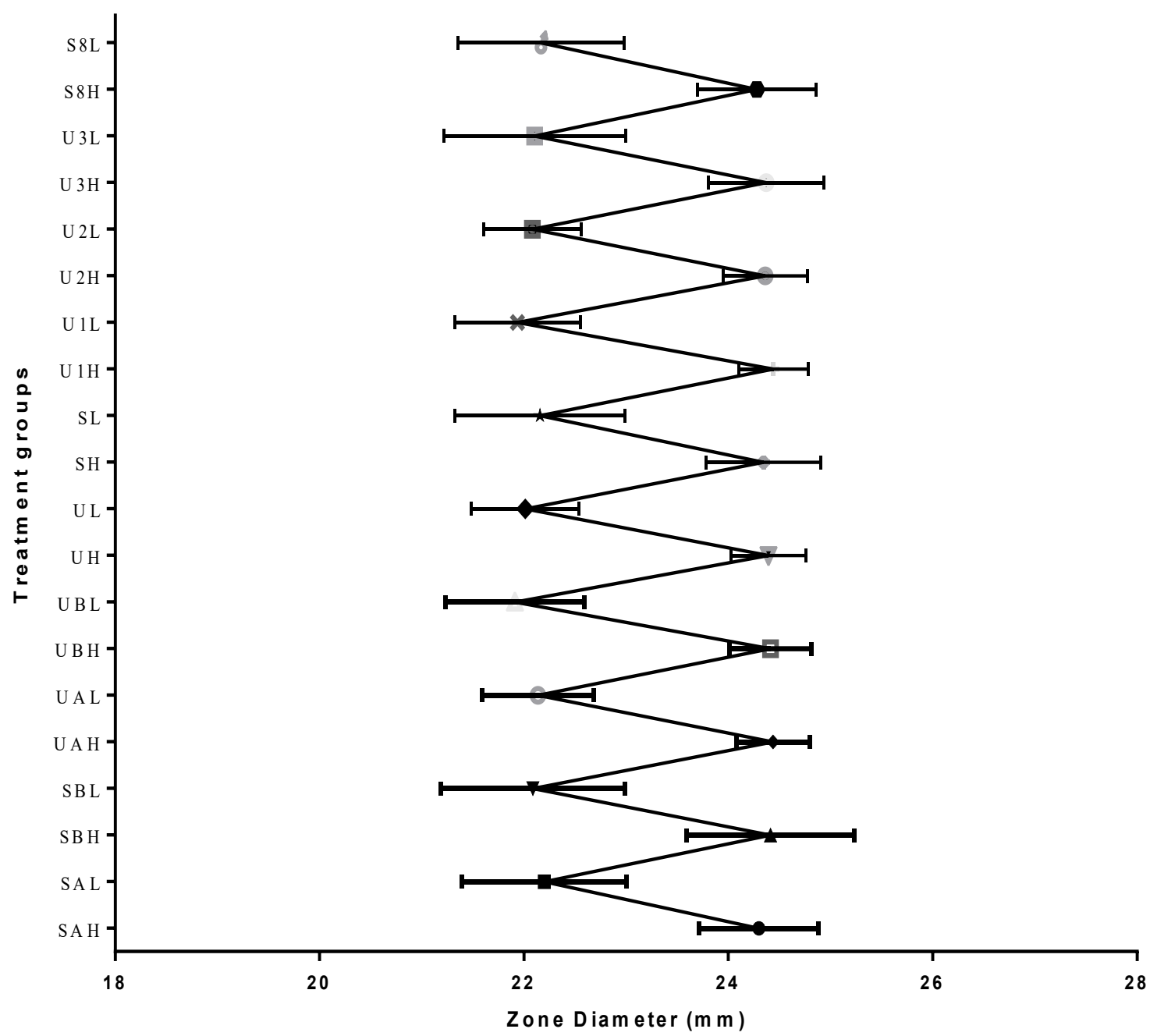

Figure 1. Means of treatment groups for three different designs \pm standard deviations (S.D.) demonstrating parallelism between standards (S) and unknowns (U) Neomycin Sulfate preparations. 
Table 2. Descriptive statistics showing comparison between treatment groups of three different designs expressed as zone of inhibition $(\mathrm{mm})$ for the same experimental subject against the same control under identical conditions.

\begin{tabular}{|c|c|c|c|c|c|c|c|c|c|c|c|c|c|c|c|c|c|c|c|c|}
\hline \multirow{2}{*}{$\begin{array}{l}\text { Design }(P \times T) \\
C S\end{array}$} & \multicolumn{8}{|c|}{$2 \times 8$} & \multicolumn{4}{|c|}{$2 \times 4$} & \multicolumn{8}{|c|}{$4 \times 8$} \\
\hline & $\mathrm{S}_{\mathrm{AH}}$ & $\mathrm{S}_{\mathrm{AL}}$ & $\mathrm{S}_{\mathrm{BH}}$ & $\mathrm{S}_{\mathrm{BL}}$ & $\mathbf{U}_{\mathrm{AH}}$ & $\mathrm{U}_{\mathrm{AL}}$ & $\mathrm{U}_{\mathrm{BH}}$ & $\mathrm{U}_{\mathrm{BL}}$ & $\mathrm{U}_{\mathrm{H}}$ & $\mathrm{U}_{\mathrm{L}}$ & $\mathrm{S}_{\mathrm{H}}$ & $\mathrm{S}_{\mathrm{L}}$ & $\mathrm{U}_{1 \mathrm{H}}$ & $\mathrm{U}_{1 \mathrm{~L}}$ & $\mathrm{U}_{2 \mathrm{H}}$ & $\mathrm{U}_{2 \mathrm{~L}}$ & $\mathrm{U}_{3 \mathrm{H}}$ & $\mathrm{U}_{3 \mathrm{~L}}$ & $\mathrm{~S}_{8 \mathrm{H}}$ & $\mathrm{S}_{8 \mathrm{~L}}$ \\
\hline NoV & 8 & 8 & 8 & 8 & 8 & 8 & 8 & 8 & 16 & 16 & 16 & 16 & 8 & 8 & 8 & 8 & 8 & 8 & 8 & 8 \\
\hline Minimum $^{3}$ & 23.40 & 20.60 & 23.10 & 20.40 & 23.90 & 21.00 & 23.90 & 21.00 & 23.90 & 21.00 & 23.40 & 20.20 & 23.91 & 20.97 & 23.88 & 21.30 & 23.50 & 20.24 & 23.36 & 20.55 \\
\hline $25 \%$ Percentile & 23.85 & 21.75 & 23.88 & 21.33 & 24.05 & 21.80 & 24.03 & 21.38 & 24.03 & 21.75 & 24.00 & 21.85 & 24.08 & 21.23 & 24.03 & 21.87 & 23.99 & 21.86 & 23.87 & 21.72 \\
\hline Median $^{3}$ & 24.30 & 22.30 & 24.45 & 22.40 & 24.55 & 22.40 & 24.45 & 21.70 & 24.45 & 22.05 & 24.45 & 22.25 & 24.57 & 22.24 & 24.25 & 22.00 & 24.43 & 22.08 & 24.28 & 22.28 \\
\hline $75 \%$ Percentile & 24.78 & 22.68 & 24.78 & 22.75 & 24.78 & 22.40 & 24.80 & 22.63 & 24.78 & 22.40 & 24.70 & 22.70 & 24.74 & 22.42 & 24.83 & 22.58 & 24.63 & 22.73 & 24.74 & 22.64 \\
\hline Maximum $^{3}$ & 25.10 & 23.30 & 25.90 & 23.00 & 24.80 & 22.70 & 25.00 & 22.90 & 24.90 & 22.80 & 25.40 & 23.30 & 24.79 & 22.44 & 24.94 & 22.76 & 25.39 & 23.20 & 25.07 & 23.27 \\
\hline Range & 1.70 & 2.70 & 2.80 & 2.60 & 0.90 & 1.70 & 1.10 & 1.90 & 1.00 & 1.80 & 2.00 & 3.10 & 0.88 & 1.47 & 1.06 & 1.46 & 1.89 & 2.96 & 1.71 & 2.72 \\
\hline $10 \%$ Percentile & 23.40 & 20.60 & 23.10 & 20.40 & 23.90 & 21.00 & 23.90 & 21.00 & 23.90 & 21.07 & 23.47 & 20.48 & 23.91 & 20.97 & 23.88 & 21.30 & 23.50 & 20.24 & 23.36 & 20.55 \\
\hline $90 \%$ Percentile & 25.10 & 23.30 & 25.90 & 23.00 & 24.80 & 22.70 & 25.00 & 22.90 & 24.90 & 22.73 & 25.19 & 23.23 & 24.79 & 22.44 & 24.94 & 22.76 & 25.39 & 23.20 & 25.07 & 23.27 \\
\hline \multicolumn{21}{|l|}{ 95\% CIoM $^{1}$} \\
\hline ACL $(\%)^{5}$ & 99.22 & 99.22 & 99.22 & 99.22 & 99.22 & 99.22 & 99.22 & 99.22 & 97.87 & 97.87 & 97.87 & 97.87 & 99.22 & 99.22 & 99.22 & 99.22 & 99.22 & 99.22 & 99.22 & 99.22 \\
\hline LCL & 23.40 & 20.60 & 23.10 & 20.40 & 23.90 & 21.00 & 23.90 & 21.00 & 24.00 & 21.70 & 24.00 & 21.80 & 23.91 & 20.97 & 23.88 & 21.30 & 23.50 & 20.24 & 23.36 & 20.55 \\
\hline UCL & 25.10 & 23.30 & 25.90 & 23.00 & 24.80 & 22.70 & 25.00 & 22.90 & 24.80 & 22.40 & 24.70 & 22.70 & 24.79 & 22.44 & 24.94 & 22.76 & 25.39 & 23.20 & 25.07 & 23.27 \\
\hline Mean & 24.30 & 22.20 & 24.41 & 22.09 & 24.44 & 22.14 & 24.41 & 21.91 & 24.39 & 22.01 & 24.34 & 22.16 & 24.44 & 21.94 & 24.36 & 22.08 & 24.37 & 22.11 & 24.28 & 22.17 \\
\hline Std. Deviation & 0.583 & 0.807 & 0.818 & 0.903 & 0.358 & 0.545 & 0.402 & 0.679 & 0.366 & 0.529 & 0.561 & 0.831 & 0.338 & 0.615 & 0.413 & 0.478 & 0.564 & 0.888 & 0.580 & 0.813 \\
\hline SEM & 0.206 & 0.285 & 0.289 & 0.319 & 0.126 & 0.192 & 0.142 & 0.240 & 0.091 & 0.132 & 0.140 & 0.207 & 0.119 & 0.217 & 0.146 & 0.169 & 0.199 & 0.313 & 0.205 & 0.287 \\
\hline LCIM 95\% & 23.81 & 21.53 & 23.73 & 21.33 & 24.14 & 21.68 & 24.08 & 21.34 & 24.20 & 21.73 & 24.04 & 21.71 & 24.16 & 21.42 & 24.01 & 21.68 & 23.90 & 21.36 & 23.79 & 21.49 \\
\hline UCIM 95\% & 24.79 & 22.87 & 25.10 & 22.84 & 24.74 & 22.59 & 24.75 & 22.48 & 24.59 & 22.29 & 24.64 & 22.60 & 24.72 & 22.45 & 24.71 & 22.48 & 24.84 & 22.85 & 24.77 & 22.85 \\
\hline $\mathrm{CV}(\%)^{6}$ & 2.400 & 3.636 & 3.352 & 4.089 & 1.466 & 2.462 & 1.645 & 3.099 & 1.500 & 2.403 & 2.304 & 3.751 & 1.383 & 2.803 & 1.695 & 2.166 & 2.315 & 4.015 & 2.391 & 3.666 \\
\hline $\mathrm{GM}^{7}$ & 24.29 & 22.19 & 24.40 & 22.07 & 24.44 & 22.13 & 24.41 & 21.90 & 24.39 & 22.01 & 24.34 & 22.14 & 24.44 & 21.93 & 24.36 & 22.08 & 24.37 & 22.09 & 24.27 & 22.15 \\
\hline GSDF ${ }^{8}$ & 1.024 & 1.038 & 1.034 & 1.043 & 1.015 & 1.025 & 1.017 & 1.031 & 1.015 & 1.024 & 1.023 & 1.039 & 1.014 & 1.029 & 1.017 & 1.022 & 1.023 & 1.042 & 1.024 & 1.038 \\
\hline LCIGM 95\% & 23.81 & 21.51 & 23.73 & 21.32 & 24.14 & 21.67 & 24.08 & 21.34 & 24.20 & 21.72 & 24.04 & 21.69 & 24.16 & 21.42 & 24.02 & 21.68 & 23.90 & 21.34 & 23.79 & 21.48 \\
\hline UCIGM 95\% & 24.79 & 22.88 & 25.09 & 22.85 & 24.74 & 22.60 & 24.75 & 22.48 & 24.59 & 22.29 & 24.64 & 22.60 & 24.72 & 22.45 & 24.70 & 22.48 & 24.84 & 22.86 & 24.77 & 22.85 \\
\hline $\mathrm{HM}^{4}$ & 24.29 & 22.17 & 24.39 & 22.05 & 24.43 & 22.13 & 24.41 & 21.89 & 24.39 & 22.00 & 24.33 & 22.13 & 24.44 & 21.92 & 24.35 & 22.07 & 24.36 & 22.07 & 24.27 & 22.14 \\
\hline LCIHM 95\% & 23.81 & 21.50 & 23.73 & 21.30 & 24.14 & 21.67 & 24.08 & 21.34 & 24.20 & 21.72 & 24.04 & 21.68 & 24.16 & 21.41 & 24.02 & 21.68 & 23.90 & 21.33 & 23.79 & 21.46 \\
\hline UCIHM 95\% & 24.79 & 22.89 & 25.09 & 22.86 & 24.74 & 22.60 & 24.75 & 22.47 & 24.59 & 22.29 & 24.63 & 22.60 & 24.72 & 22.46 & 24.70 & 22.48 & 24.84 & 22.87 & 24.76 & 22.86 \\
\hline $\mathrm{QM}^{2}$ & 24.31 & 22.21 & 24.42 & 22.10 & 24.44 & 22.14 & 24.42 & 21.92 & 24.40 & 22.02 & 24.35 & 22.17 & 24.44 & 21.94 & 24.36 & 22.09 & 24.38 & 22.12 & 24.29 & 22.18 \\
\hline LCIQM 95\% & 23.81 & 21.54 & 23.73 & 21.35 & 24.14 & 21.69 & 24.08 & 21.34 & 24.20 & 21.74 & 24.05 & 21.73 & 24.16 & 21.43 & 24.01 & 21.68 & 23.90 & 21.38 & 23.80 & 21.50 \\
\hline UCIQM 95\% & 24.79 & 22.87 & 25.10 & 22.83 & 24.74 & 22.59 & 24.75 & 22.48 & 24.59 & 22.30 & 24.65 & 22.60 & 24.72 & 22.45 & 24.71 & 22.48 & 24.85 & 22.84 & 24.77 & 22.84 \\
\hline Skewness ${ }^{9}$ & -0.173 & -1.011 & 0.298 & -1.132 & -0.557 & -1.536 & 0.249 & 0.321 & 0.020 & -0.590 & 0.036 & -1.084 & -0.674 & $4-0.938$ & 0.523 & 0.170 & 0.347 & -1.295 & -0.217 & $7-1.041$ \\
\hline Kurtosis ${ }^{10}$ & -1.221 & 1.754 & 1.247 & 0.331 & -1.504 & 2.214 & -1.166 & -1.291 & -1.599 & $9-0.261$ & -0.585 & 1.285 & -1.262 & -0.983 & -1.382 & 0.188 & 0.862 & 2.734 & -1.112 & 21.816 \\
\hline
\end{tabular}

${ }^{1}$ Confidence Interval $=$ Sample mean $\pm \mathrm{t} x$ Std . Deviation/Square root of sample size, with $\mathrm{t}$-value for $95 \%$ confidence $=2.262$.

${ }^{2}$ Calculate the square of every reading, then take the average of the squares and finally compute the square root of this mean.

${ }^{3} \mathrm{R}=\mathrm{P} \times(\mathrm{n}+1) / 100$, where; $\mathrm{P}=$ Desired percentile and $\mathrm{n}=$ Number of values in the data set.

${ }^{4}$ Reciprocal of the mean of the reciprocal of the values in each treatment.

${ }^{5}$ Dependent on the precise values of numerator and denominator.

${ }^{6}$ Relative Variability $=$ Std. Deviation/ Mean (expressed either as a fraction or a percent).

${ }^{7}$ Calculated by taking the average of the logarithms of the whole dataset, then calculating the antilog of the mean. 
8 The firsts step is to transform all the readings to logarithm values, calculate the sample Std. Deviation of these log sets, and then converting to the antilogarithm of those Std. Deviation.

${ }^{9}$ Quantification of the distribution symmetry. The ideal distribution which should be symmetrical possesses a skewness of zero.

${ }^{10}$ Measure how the tails of the dataset distribution are close to the perfect Gaussian spreading. That distribution has a kurtosis of zero.

ACL: Actual Confidence Level. CIoM: Confidence Interval of Median. CV: Coefficient of Variation. GM: Geometric Mean. GSDF: Geometric SD factor. HM: Harmonic mean. LCIGM 95\%: Lower 95\% CI of geo. Mean. LCIHM 95\%: Lower 95\% CI of harm. Mean. $\quad$ LCIM 95\%: Lower 95\% CI of mean. LCIQM 95\%: Lower 95\% CI of quad. Mean. LCL: Lower Confidence Limit. NOV: Number of Values. CS: Column Statistics. Px T: Preparations and Treatments. QM: Quadratic mean. SEM: Standard Error of Mean. UCIGM 95\%: Upper 95\% CI of geo. Mean. UCL: Upper Confidence Limit. UCIHM 95\%: Upper 95\% CI of harm. Mean. UCIM 95\%: Upper 95\% CI of mean. UCIQM 95\%: Upper $95 \%$ CI of quad. Mean.
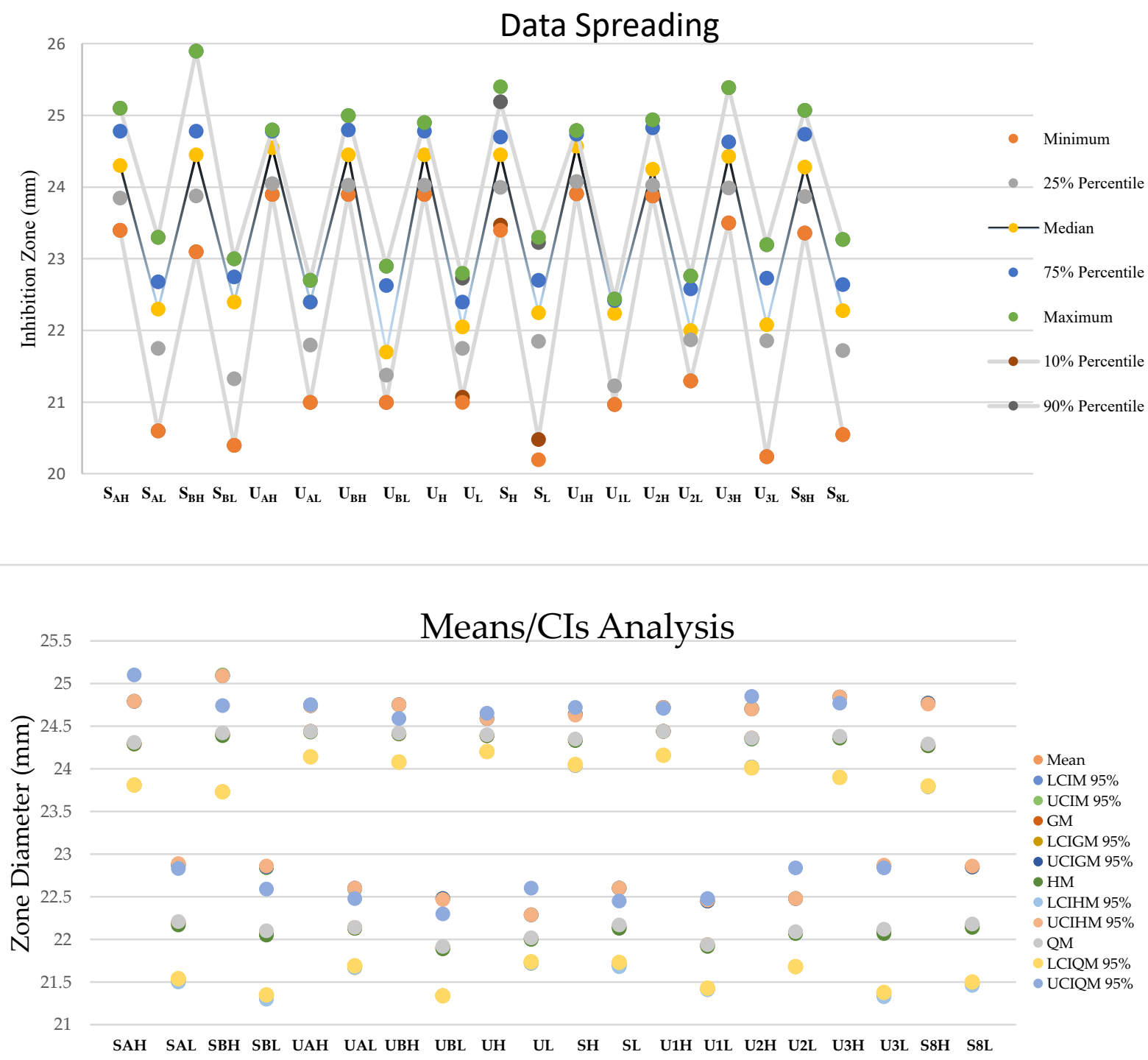

Figure 2. Visual descriptive analysis of data distribution for each treatment group of each antibiotic assay design showing dispersion pattern and the means with $95 \%$ CIs. 


\section{Normal QQ plot}

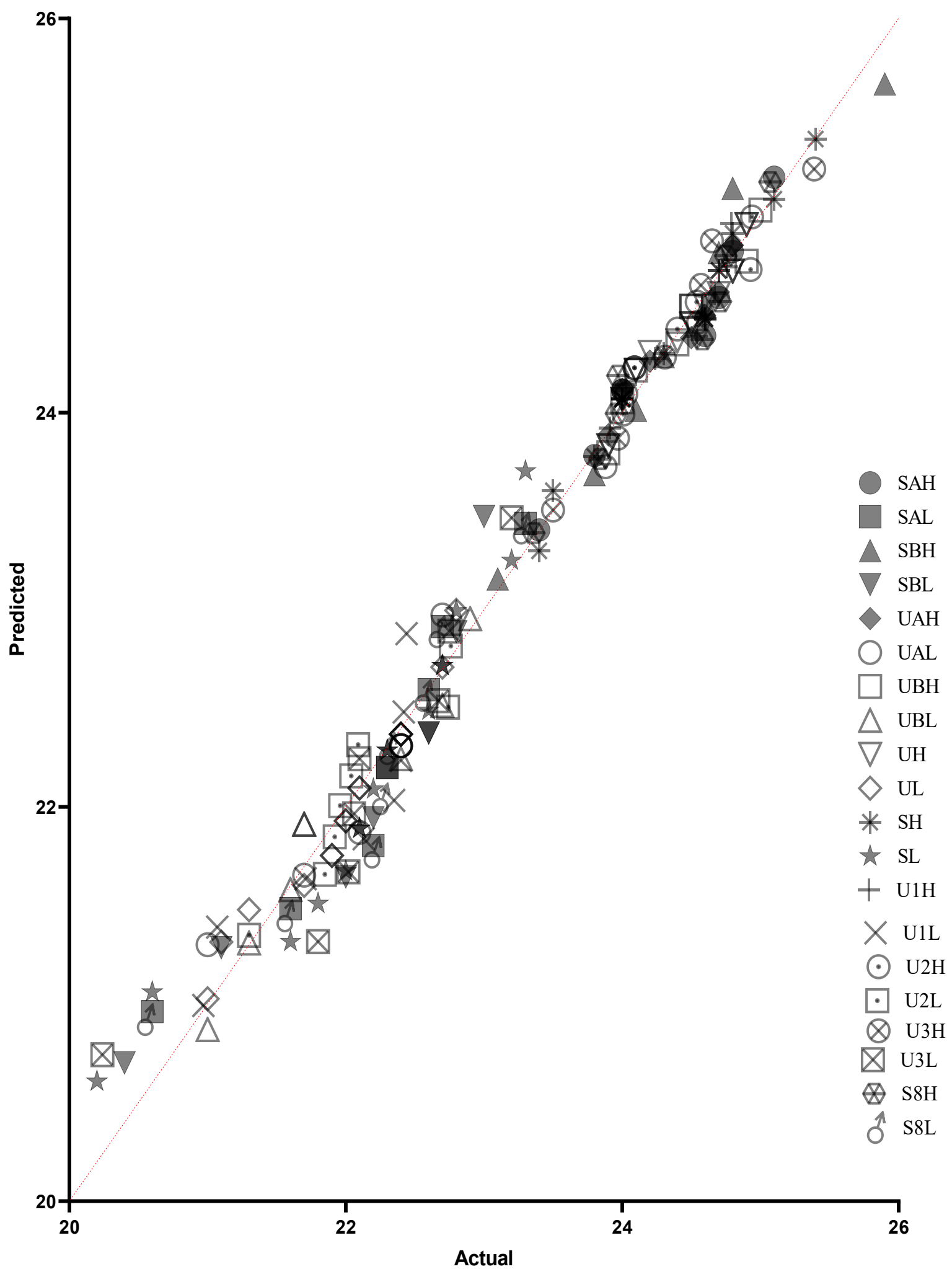

Figure 3. Scatter probability graph showing normality of the zone inhibition groups for assay designs of two preparations, (a) eight and (b) four treatments. 
Test for Equal Variances: UH, UL, SH, SL Multiple comparison intervals for the standard deviation, $\alpha=0.05$

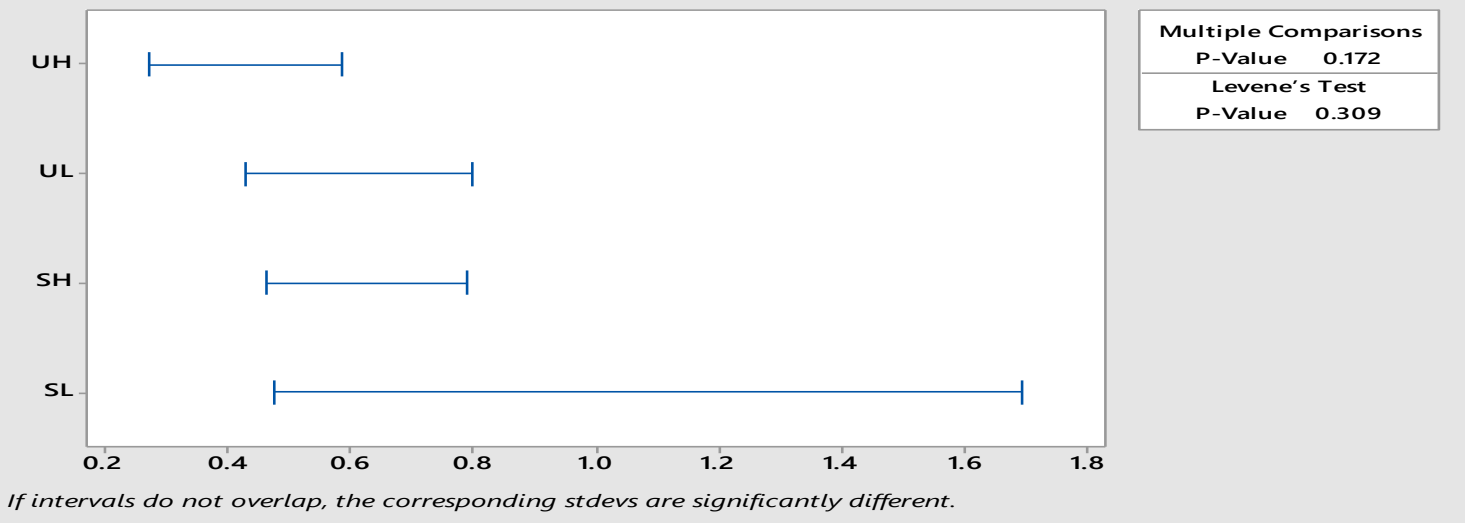

Figure 4. Homogeneity of variances test of two preparations $x$ four treatments assay design, showing: equality of variances: significance of differences for standard deviations.

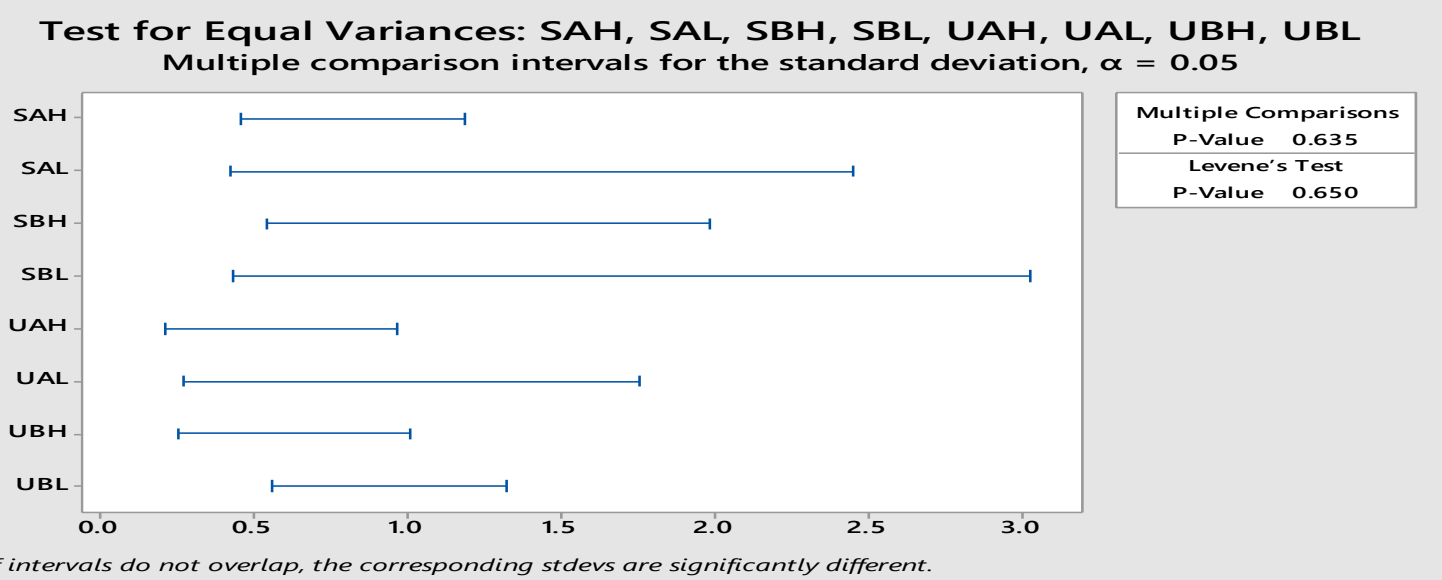

Figure 5. Homogeneity of variances test of two preparations $x$ eight treatments assay design, showing: (equality of variances: significance of differences for standard deviations.

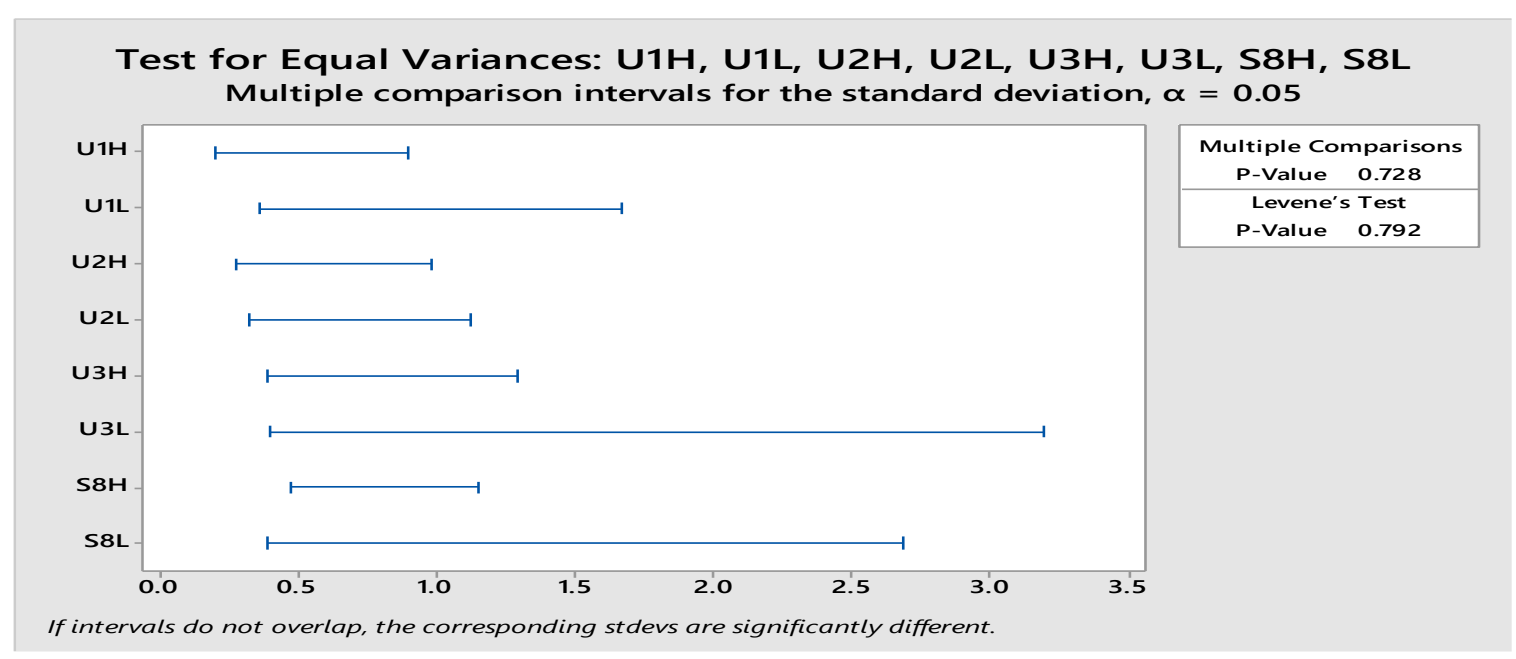

Figure 6. Homogeneity of variances test of two preparations x eight treatments assay design, showing: equality of variances: significance of differences for standard deviations. 
Table 4. Analysis of variance report of two-dose level assay using a square plate and $8 \times 8$ Latin square $2 \times 4$ design.

\begin{tabular}{|c|c|c|c|c|c|c|}
\hline Source of Variance & d.f. & Sum of Squares & $\begin{array}{l}\text { Mean } \\
\text { Square }\end{array}$ & $\begin{array}{c}\text { Variance Ratio } \\
\text { (F-value) }\end{array}$ & $\begin{array}{c}\text { Limiting } \\
\text { Value }\end{array}$ & $\begin{array}{l}\text { Calculated } \\
\text { Probability }\end{array}$ \\
\hline Derivative from Raw Total & 7 & 2.79 & 0.40 & 1.129 & $<2.22$ & 0.3618 \\
\hline Derivative from Column Total & 7 & 2.09 & 0.30 & 0.844 & $<2.22$ & 0.5573 \\
\hline Derivative from Treatment Total & 3 & 84.10 & & & & \\
\hline Derivative from Preparation Total & 1 & 0.01 & 0.01 & 0.030 & $<4.05$ & 0.8622 \\
\hline Regression Squares & 1 & 83.93 & 83.93 & 237.624 & $>4.05$ & 0.0000 \\
\hline Parallelism Squares & 1 & 0.16 & 0.16 & 0.462 & $<4.05$ & 0.5003 \\
\hline Residual Error (SSreg) & 46 & 16.25 & 0.35 & 1.000 & $<1.63$ & \\
\hline Total (SStot) & 63 & 105.23 & & & & \\
\hline
\end{tabular}

Table 5. Analysis of variance report of two-dose level assay using a square plate and 4 × 8 Latin square $2 \times 8$ design.

\begin{tabular}{lcccccc}
\hline Source of Variance & d.f. & Sum of Squares & $\begin{array}{c}\text { Mean } \\
\text { Square }\end{array}$ & $\begin{array}{c}\text { Variance Ratio } \\
\text { (F-value) }\end{array}$ & $\begin{array}{c}\text { Limiting } \\
\text { Value }\end{array}$ & $\begin{array}{c}\text { Calculated } \\
\text { Probability }\end{array}$ \\
\hline Derivative from Raw Total & 7 & 2.79 & 0.40 & 1.04 & $<2.24$ & 0.6461 \\
Derivative from Column Total & 7 & 2.09 & 0.30 & 0.78 & $<2.24$ & 0.7930 \\
\hline Derivative from Treatment Total & 7 & 84.26 & & & & \\
\hline Derivative from Preparation Total & 3 & 0.02 & 0.01 & 0.018 & $<2.83$ & 0.2761 \\
Regression Squares & 1 & 83.93 & 83.93 & 219.13 & $>12.52$ & 0.0000 \\
Parallelism Squares & 3 & 0.31 & 0.16 & 0.27 & $<2.83$ & 0.7138 \\
Residual Error (SSreg) & 42 & 16.09 & 0.35 & 1.00 & $<1.67$ & \\
Total (SStot) & 63 & 105.23 & & & & \\
\hline
\end{tabular}

Table 6. Analysis of variance report of two-dose level assay using a square plate and $8 \times 8$ Latin square $2 \times 8$ design.

\begin{tabular}{lcccccc}
\hline Source of Variance & d.f. & Sum of Squares & $\begin{array}{c}\text { Mean } \\
\text { Squares }\end{array}$ & $\begin{array}{c}\text { Variance } \\
\text { Ratio }\end{array}$ & $\begin{array}{c}\text { Limiting } \\
\text { Value }\end{array}$ & $\begin{array}{c}\text { Calculated } \\
\text { Probability }\end{array}$ \\
\hline Preparation & 1 & 0.16 & 0.16 & 0.42 & $<4.07$ & 0.5229 \\
Regression & 1 & 84.94 & 84.94 & 217.09 & $>12.52$ & 0.0000 \\
Parallelism (deviation from) & 1 & 0.14 & 0.14 & 0.35 & $<4.07$ & 0.5587 \\
Contrast of standard & 1 & 0.00 & 0.00 & 0.00 & $<1.70$ & 0.9485 \\
Contrast of unknown & 1 & 0.16 & 0.16 & 0.41 & $<1.70$ & 0.5265 \\
Contrast of standard slope & 1 & 0.08 & 0.08 & 0.20 & $<1.70$ & 0.6555 \\
Contrast of unknown slope & 1 & 0.08 & 0.08 & 0.20 & $<1.70$ & 0.6535 \\
\hline Subtotal & 7 & 85.40 & & & $<2.24$ & 0.1067 \\
Treatments & 7 & 85.40 & & & $<2.24$ & 0.3376 \\
\hline Rows & 7 & 5.01 & 0.72 & 1.83 & & \\
Columns & 7 & 3.22 & 0.46 & 1.18 & 1.00 & \\
\hline Error by difference & 42 & 16.43 & 0.39 & & & \\
Total & 63 & 110.06 & & & & \\
\hline
\end{tabular}




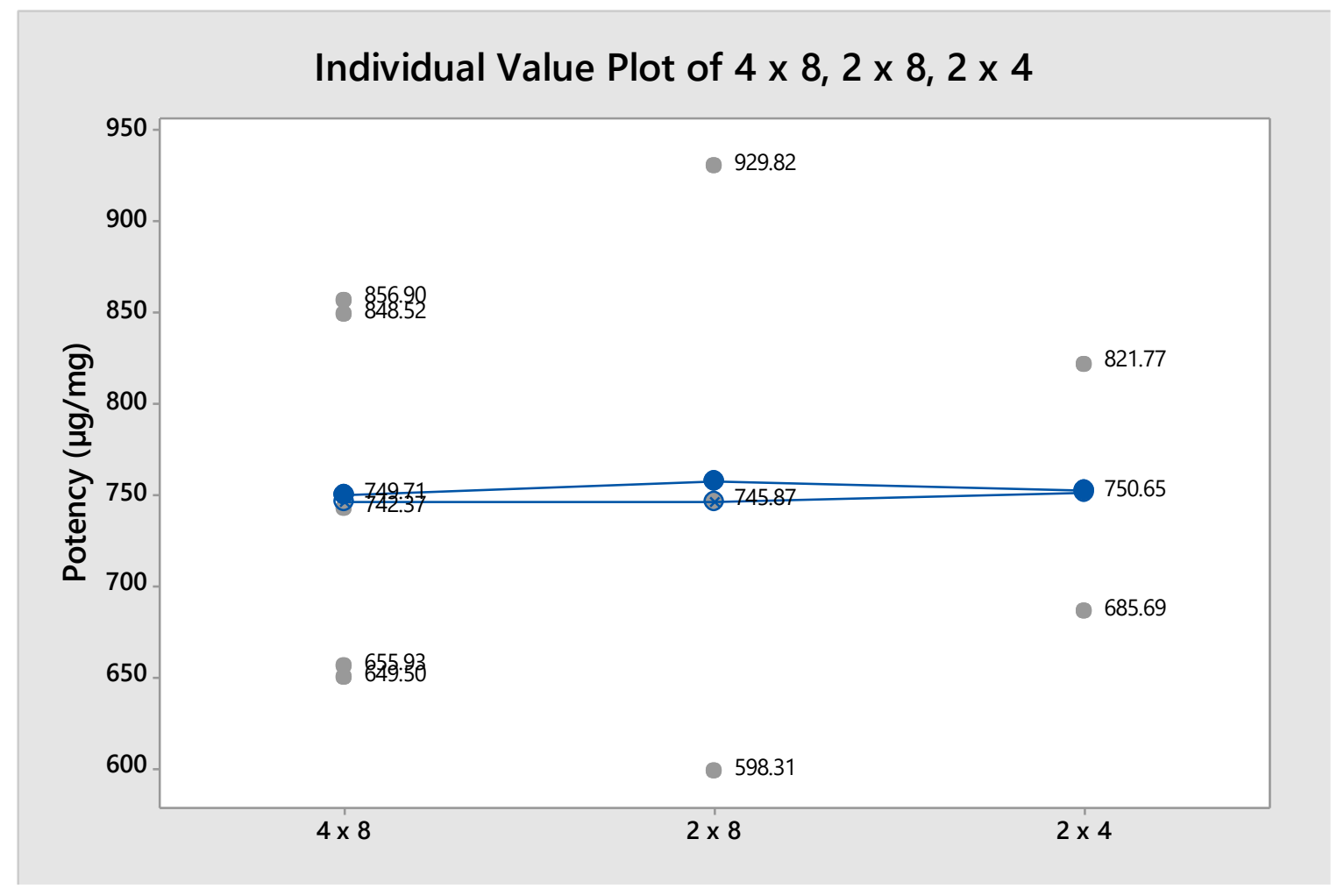

Activity/Confidence Lim its

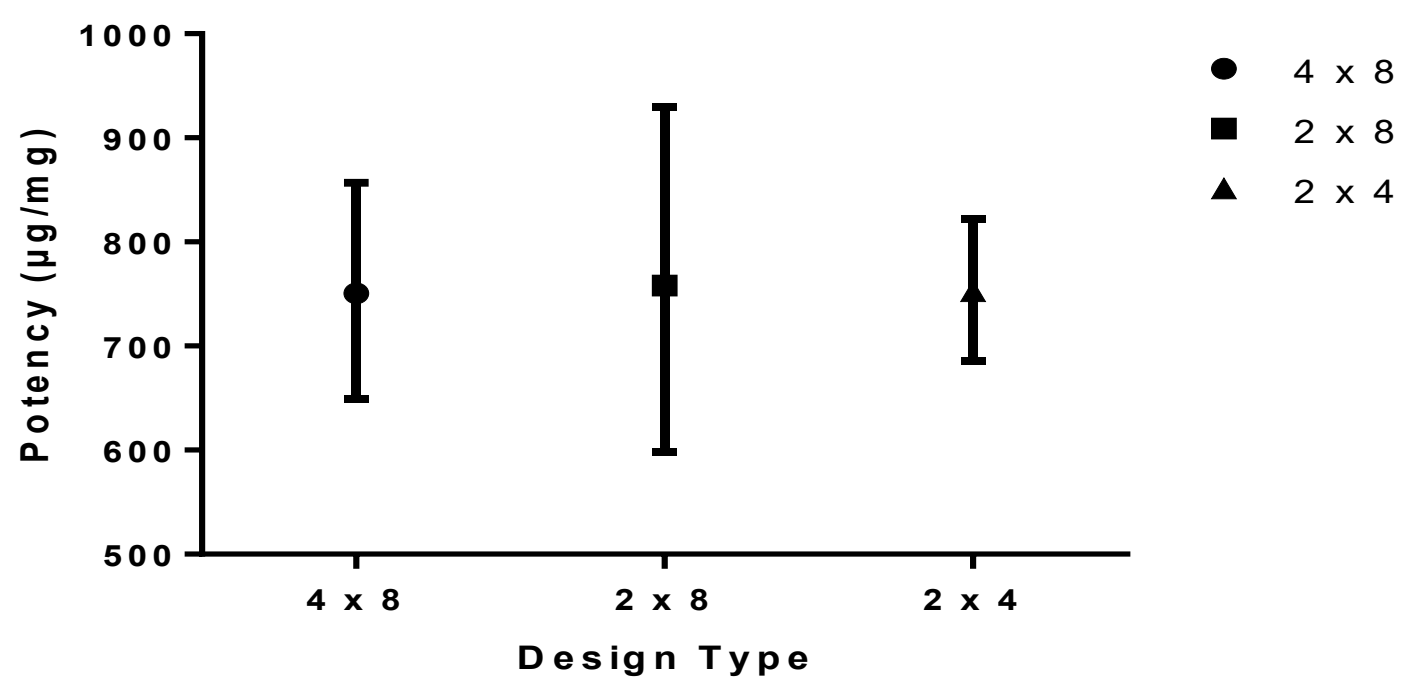

Figure 7. Mean and range graph showing the estimated confidence limits of the potency for three design types of microbiological assays presented as Individual and mean/range plots.

\section{Discussion}

Agar diffusion assay was known to be one of the most commonly used quality control (QC) testing for the determination of the antimicrobial potency of the antibiotic substance [27]. To date, the true antibiotic activity of Neomycin Sulfate must be officially determined using microbiological analysis [28]. This would be crucial as this antibiotic was added in "antibiotics and vitamins of the b group" from the WHO index of degradable substances [6]. This two-dose symmetrical PLM was statistically evaluated through four and eight treatments for two and four preparations. The stepwise statistical intervention 
would serve as the basis for both the verification of the validity of the assay data - and hence the experimental model - for the regular testing of the drug potency and preferential comparison between the selected modules for the quality of the results obtained [8]. Ensuring the validity of the analysis system is a crucial step before drawing any results and/or conclusions from the test. Commercially available programs for the calculations should be assessed critically. The prepared Excel workbook designed for the potency assessment and determination was evaluated against already comprehensively expressed examples step-by-step to ensure the validity of software for computation.

\subsection{Initial statistical investigation of the suitability of the assay output results}

Initial examination of the raw data would be mandatory to exclude any unusual record from the dataset for this initial step. This could be followed by the investigation of the sources of the variation in the testing using ANOVA [29]. Statistical analysis of the raw data should reveal a dataset pattern that would be trustworthy to proceed in further computation to study the suitability of the assay design for potency calculation of the subject material [30]. The recorded datasets were the measured zone of inhibition diameter produced by the diffusion of the antibiotic through the agar matrix measured to the nearest $0.01 \mathrm{~mm}$.

\subsubsection{Overview of the pattern of treatment groups}

The descriptive statistical study was essential in this study to detect and exclude any aberrant observations before further processing of the datasets which have been derived from the original raw data measured from the antibiotic plates [31]. While parallelism could be assessed statistically, it might be easily investigated visually using the graphical presentation of the successive high and low doses (Figure 1) [32]. In addition, a combination of tabulated and illustrative analysis of each treatment group might show the spreading, pattern and homogeneity of the records. At this stage, the clustering tendency of data could be detected which would explain an apparent outlier value as in Figure 2 [6]. While the general statistical description provided herein was comprehensive for clarity and demonstration, the actual routine preliminary analysis might make use of significantly reduced diversification in the examination of the datasets.

\subsubsection{Normality of the treatment group datasets}

While small deviation in the normality of data might not encounter a serious problem in the result interpretation [32]. It would be plausible to track - from time to time with reasonable frequency - the state of data distribution. An array of tests was used for a comparative study of the normality behavior. Yet, the Shapiro-Wilk normality test was considered as an official one for treatment groups with seven or more replicates [31]. Clustering patterns might show extreme values as excursions even if they were not true aberrant values (known by experience from the trending history of data). In turn, this behavior would influence the normality test results by affecting the expected shape of the standard expected bellshaped of the Gaussian pattern of the distribution. Nevertheless, it should be understood that the actual distributions in real and practical experimentation would be expected to not follow the exact theoretically hypothesized dispersion and deviations that were common in study groups [33-35]. However, these deviations should be considered statistically within a reasonable range.

\subsubsection{Outlier evaluation in each treatment group}

As discussed earlier, outliers had an impact on data and their statistical evaluation. However, it should be highlighted that rejection and removal of the aberrant values blindly based solely on the outcome of the test would be a discouraging practice [36]. Each situation of detection and removal of the outlier should be evaluated case-by-case to ensure the avoidance of unintended bias that would lead to the omission of a truly valid result as it could be found in the current case [6,36]. The decision of canceling the rejection action - based on the previous experience - was supported by another battery of tests despite the fact that the compendial method was the original source of this marginal alarm for the excursion. Again, this might happen due to a possible clustering tendency in the datasets [6]. 


\subsubsection{Analysis of homoscedasticity in the experimental designs}

Homoscedasticity is another criterion that should be investigated between the treatment groups of the antibiotic potency assay experiment. Homogeneity of variances might be checked by either Bartlett's test or Cochran's test [31]. These appeared to be little used in the microbiological assay and so were not considered here. For further information, the referencing to the European Pharmacopoeia might be consulted [6,32]. However, it was noteworthy that Bartlett's test was criticized by Box (1953) as being not robust to non-normality. The author compared it with "putting to sea in a rowing boat to see if conditions were fit for an ocean liner to leave port" [6]. In the present work, a different test was used that was found convenient in terms of simplicity of implementation and ease of interpretation. Levene's test had the advantage of being less sensitive for the departure from normality than Bartlett's test [37].

\subsection{Statistical investigation of the sources of variations}

After ensuring the quality and validity of the recorded results of the inhibition zone for further processing. It would be mandatory to examine the validity of the assay and to determine its suitability to calculate the potency of the sample under examination [36]. Otherwise, the estimated activity might be inaccurate. Identification of the sources of variations per an assay design was essential to control the possible sources of errors and investigate any abnormal result or outcome [8]. There were common criteria to be examined both official (regression and parallelism) and ono-official (preparation, row and column) [8]. There might be special criteria for a specific design such as that for $2 \times 8$ assay as there was contrast analysis for both duplicate standard and test with their slopes [6]. An acceptable ANOVA result would deliver a solid estimate for the potency of the examined antimicrobial material. These sources of variances were evident in Figures 4, 5 and 6.

\subsection{Final result of antimicrobial activity evaluation for each design}

Under identical experimental conditions, the results of potency determination for Neomycin Sulfate (expressed as $\mu \mathrm{g} / \mathrm{mg}$ ) were reasonably close within the three-experimental layout designs. Figure 7 demonstrated variable confidence intervals between them. When high confidence would be desirable, a modification in the assay test might be required $[6,26]$. To reach this goal. It would be necessary to align this criterion with the main purpose of the antibiotic assay [38]. Thus, a design that was aimed to screen the compounds for the antimicrobial activity should be different from that was designed for estimation of the activity of the product in the bulk or finished pharmaceutical preparations. Increasing the number of replicates for each treatment group must be considered as an important factor.

\section{Conclusions}

The current study provided an example for the quantitative assessment of the suitability of the testing system designs to determine the potency of the Active Pharmaceutical Ingredient (API) using PLM of 2 $\mathrm{x} 2$ assay. In the present case of Neomycin Sulfate, the two-dose balanced experiment for three different designs in large rectangular antibiotic plates showed acceptable system suitability of $2 \times 4,2 \times 8$ and $4 \times$ 8 for preparations $x$ treatments. While the variation in the potency determination was $<5.0 \%$, the differences in the confidence limits were noticeable. Further study would be necessary to control experimental designs and conditions such as the number of replicates to bring the confidence range within the desired window depending on the main purpose and the target from the activity measurements. In the present situation, the $2 \times 4$ assay design showed a tighter confidence window in comparison to the $2 \times 8$ design. Long-term monitoring of the potency determination test using the current methodology might provide solid evidence for the adjustment and fine-tuning of the experiment layout design. Thus, the trending of data using control charts would assist the evaluation of the assay through a comparative study. 
Author Contributions: Conceptualization, D.E and E.R; methodology, M.E; software, M.E; validation, E.R, D.E and M.E; formal analysis, M.E; investigation, E.R; resources, D.E; data curation, M.E; writingoriginal draft preparation, M.E; writing - review and editing, E.R; visualization, E.R; supervision, E.R; project administration, Dalia Eissa; funding acquisition, Dalia Eissa. All authors have read and agreed to the published version of the manuscript.

Funding: This work is supported by authors only without any external fund.

Acknowledgments: None to declare.

Conflicts of Interest: the authors declare that there is no competing conflict of interest.

\section{References}

[1] S. Gad, "Pharmaceutical manufacturing handbook: production and processes", Wiley-Interscience, 2008.

[2] R. Unissa, M. Sudhakar and M. Hadi, "Lab Manual for Pharmaceutical Microbiology”, 1st ed. Ahmedabad: Nirav and Roopal Prakashan, 2011.

[3] V. Fedorenko et al., "Antibacterial discovery and development: from gene to product and back", BioMed Research International, vol. 2015, pp. 1-16, 2015. Available: 10.1155/2015/591349.

[4] Technical Guide for the elaboration of monographs, "European Pharmacopoeia", Edqm.eu, 2011. [Online]. Available: https://www.edqm.eu/medias/fichiers/technical_guide_for_the_elaboration_of_monographs_pdf. [Accessed: 30- Aug2021].

[5] Health Ministers of the United Kingdom, "British Pharmacopoeia", 3rd ed. London: Medicines and Healthcare Products Regulatory Agency, 2021.

[6] W. Hewitt, "Microbiological assay for pharmaceutical analysis: a rational approach”, Boca Raton, Fla: Interpharm/CRC, 2004 .

[7] Pharmacopeial Forum, "The United States pharmacopoeia", 43rd ed. North Bethesda, Maryland, United States: United States Pharmacopeial Convention, Vol. 44(6), 2021.

[8] W. Hewitt, "Microbiological Assay", Saint Louis: Elsevier Science, 2014.

[9] J. Lightbown, "Biological standardisation and the Analyst. A review", The Analyst, vol. 86, no. 1021, p. 216 , 1961. Available: 10.1039/an9618600216

[10] W. Sokolski, C. Chidester, O. Carpenter and W. Kaneshiro, "Assay Methods for Total Neomycins B and C", Journal of Pharmaceutical Sciences, vol. 53, no. 7, pp. 826-828, 1964. Available: 10.1002/jps.2600530731.

[11] W. Köhler, "Who Expert Committee on Biological Standardization, 23. Report (WHO Techn. Rep. Ser. No. 463). 120. Genf 1970: World Health Organization", Zeitschrift für allgemeine Mikrobiologie, WHO/BS/70.1001., pp. 255-255, 1971. Available: 10.1002/jobm.19680080326.

[12] W. Wilson, G. Richard and D. Hughes, "Thin-layer chromatographic identification of the gentamicin complex", Journal of Chromatography A, vol. 78, no. 2, pp. 442-444, 1973. Available: 10.1016/s0021-9673(73)30103-0.

[13] L. Clontz," Microbial limit and bioburden tests", Boca Raton: CRC Press, 2009.

[14] WHO, “The International pharmacopoeia”, Geneva: World Health Organization, 2006.

[15] C. Sheehan, "Overview of International Harmonization through the Pharmacopeial Discussion Group", Usp.org, 2014. [Online]. Available: https://www.usp.org/sites/default/files/usp/document/get-involved/stakeholder-forums/2bexcipients-and-harmonzation-overview-2014-02-19.pdf. [Accessed: 01- Sep- 2021].

[16] Technical Data, "Antibiotic Assay Medium F", Himedialabs.com, 2020. [Online]. Available: https://himedialabs.com/TD/M923.pdf. [Accessed: 01- Sep- 2021]. 
[17] Pharmaceutical Secondary Standard; Certified Reference Material, "Neomycin Sulfate Pharmaceutical Secondary Standard; Certified Reference Material I Sigma-Aldrich", Sigmaaldrich.com, 2021. [Online]. Available: https://www.sigmaaldrich.com/EG/en/product/sial/phr1491. [Accessed: 01- Sep- 2021].

[18] C. Valgas, S. Souza, E. Smânia and A. Smânia Jr., "Screening methods to determine antibacterial activity of natural products", Brazilian Journal of Microbiology, vol. 38, no. 2, pp. 369-380, 2007. Available: 10.1590/s151783822007000200034 .

[19] J. Hudzicki, "Kirby-Bauer Disk Diffusion Susceptibility Test Protocol", Asm.org, 2009. [Online]. Available: https://asm.org/getattachment/2594ce26-bd44-47f6-8287-0657aa9185ad/Kirby-Bauer-Disk-Diffusion-Susceptibility-TestProtocol-pdf.pdf. [Accessed: 01- Sep- 2021].

[20] GraphPad Software LLC, "GraphPad Prism 9 User Guide - Welcome to Prism 9 User Guide", Graphpad.com, 2021. [Online]. Available: https://www.graphpad.com/guides/prism/latest/user-guide/index.htm. [Accessed: 01- Sep- 2021].

[21] M. Evans, G. McCabe and D. Moore, "Minitab manual for Moore and McCabe's Introduction to the practice of statistics", third edition. New York: W.H. Freeman, 1999.

[22] W. Winston, “Microsoft excel 2016”, Redmond, Washington: Microsoft, 2016.

[23] C. Carlberg, "Statistical analysis", Indianapolis, Indiana: Que, 2018.

[24] T. Oppe, J. Menegola and E. Schapoval, "MICROBIOLOGICAL ASSAY FOR THE DETERMINATION OF CEFPIROME IN RAW MATERIAL AND INJECTABLE PREPARATION", Drug Analytical Research, vol. 2, no. 1, pp. 29-35, 2018. Available: 10.22456/2527-2616.84473.

[25] S. Nahar, M. Khatun and M. Kabir, "Application of microbiological assay to determine the potency of intravenous antibiotics", Stamford Journal of Microbiology, vol. 10, no. 1, pp. 25-29, 2020. Available: 10.3329/sjm.v10i1.50729.

[26] A. Zuluaga, M. Agudelo, C. Rodriguez and O. Vesga, "Application of microbiological assay to determine pharmaceutical equivalence of generic intravenous antibiotics", BMC Clinical Pharmacology, vol. 9, no. 1, 2009. Available: 10.1186/14726904-9-1.

[27] E. Cazedey and H. Salgado, "Development and Validation of a Microbiological Agar Assay for Determination of Orbifloxacin in Pharmaceutical Preparations", Pharmaceutics, vol. 3, no. 3, pp. 572-581, 2011. Available: 10.3390/pharmaceutics3030572.

[28] N. Dafale, U. Semwal, P. Agarwal, P. Sharma and G. Singh, "Development and validation of microbial bioassay for quantification of Levofloxacin in pharmaceutical preparations", Journal of Pharmaceutical Analysis, vol. 5, no. 1, pp. 1826, 2015. Available: 10.1016/j.jpha.2014.07.007.

[29] F. Rebello Lourenco, M. Augusto Lyrio Traple, R. Takao Okamoto and T. de Jesus Andreoli Pinto, "Development and Validation of Microbiological Assay for Ceftriaxone and its Application in Photo-stability Study", Current Pharmaceutical Analysis, vol. 9, no. 1, pp. 77-81, 2013. Available: 10.2174/1573412911309010011.

[30] T. Mzolo, Statistical methods for the analysis of bioassay data. Technische Universiteit Eindhoven, 2016.

[31] F. Lourenço and T. Pinto, "Comparison of three experimental designs employed in gentamicin microbiological assay through agar diffusion", Brazilian Journal of Pharmaceutical Sciences, vol. 45, no. 3, pp. 559-566, 2009. Available: $10.1590 /$ s1984-82502009000300022.

[32] Statistical analysis, "STATISTICAL ANALYSIS OF RESULTS OF BIOLOGICAL ASSAYS AND TESTS", Uspbpep.com, 2008. [Online]. Available: http://www.uspbpep.com/ep60/5.3.\%20\%20statistical\%20analysis\%20of\%20results\%20of \%20biological\% 20assays\%20and\%20tests\%2050300e.pdf. [Accessed: 01- Sep- 2021]. 
[33] M. Eissa, A. Mahmoud and A. Nouby, "Control Chart in Microbiological Cleaning Efficacy of Pharmaceutical Facility", Dhaka University Journal of Pharmaceutical Sciences, vol. 14, no. 2, pp. 133-138, 2016. Available: 10.3329/dujps.v14i2.28501.

[34] M. Eissa, "Application of Laney control chart in assessment of microbiological quality of oral pharmaceutical filterable products", Bangladesh Journal of Scientific and Industrial Research, vol. 52, no. 3, pp. 239-246, 2017. Available: 10.3329/bjsir.v52i3.34160.

[35] M. Essam Eissa, "Determination of the Microbiological Quality of Feed City Water to Pharmaceutical Facility: Distribution Study and Statistical Analysis", ATHENS JOURNAL OF SCIENCES, vol. 4, no. 2, pp. 143-160, 2017. Available: 10.30958/ajs.4-2-4.

[36] M. Essam Eissa, "Suitability system of microbiological method for nystatin potency determination in the routine analysis using agar diffusion method", SciMedicine Journal (SMJ), in press.

[37] Engineering Statistics Handbook, "1.3.5.10. Levene Test for Equality of Variances", Itl.nist.gov, 2021. [Online]. Available: https://www.itl.nist.gov/div898/handbook/eda/section3/eda35a.htm. [Accessed: 01- Sep- 2021].

[38] M. Essam Eissa, "Validation of symmetrical two-dose parallel line assay model for nystatin potency determination in pharmaceutical product", Journal of Advanced Pharmacy Research (JAPR), in press. 